\title{
Modelling of cirrus clouds - Part 2: Competition of different nucleation mechanisms
}

\author{
P. Spichtinger ${ }^{1}$ and K. M. Gierens ${ }^{2}$ \\ ${ }^{1}$ Institute for Atmospheric and Climate Science, ETH Zurich, 8092 Zurich, Switzerland \\ ${ }^{2}$ Deutsches Zentrum für Luft- und Raumfahrt, Institut für Physik der Atmosphäre, Oberpfaffenhofen, Germany
}

Received: 4 March 2008 - Published in Atmos. Chem. Phys. Discuss.: 20 May 2008

Revised: 4 November 2008 - Accepted: 24 March 2009 - Published: 1 April 2009

\begin{abstract}
We study the competition of two different freezing mechanisms (homogeneous and heterogeneous freezing) in the same environment for cold cirrus clouds. To this goal we use the recently developed and validated ice microphysics scheme (Spichtinger and Gierens, 2009a) which distinguishes between ice classes according to their formation process. We investigate cases with purely homogeneous ice formation and compare them with cases where background ice nuclei in varying concentration heterogeneously form ice prior to homogeneous nucleation. We perform additionally a couple of sensitivity studies regarding threshold humidity for heterogeneous freezing, uplift speed, and ambient temperature, and we study the influence of random motions induced by temperature fluctuations in the clouds. We find three types of cloud evolution, homogeneously dominated, heterogeneously dominated, and a mixed type where neither nucleation process dominates. The latter case is prone to long-lasting in-cloud ice supersaturation of the order $30 \%$ and more.
\end{abstract}

\section{Introduction}

Cirrus clouds are like other clouds important modulators of the radiation budget of the Earth-atmosphere system. However, the mean impact of cirrus on Earth's climate is still unclear, although a net warming seems probable (Chen et al., 2000). A recent study (Fusina et al., 2007) on the radiative impact of thin midlatitude cirrus clouds shows that the transition from a net warming to a net cooling depends crucially on the number density of ice crystals, which in turn depends

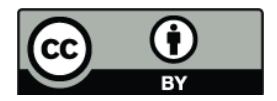

Correspondence to: P. Spichtinger (peter.spichtinger@env.ethz.ch) sensitively on cooling rates (Haag and Kärcher, 2004) and the ice crystal formation mechanism.

There are two classes of ice formation mechanisms in the low temperature range $\left(T<-38^{\circ} \mathrm{C}\right)$, namely heterogeneous nucleation and homogeneous freezing of solution droplets (for a definition of these notions see Vali, 1985; Koop , 2004). While homogeneous freezing requires ice supersaturation in excess of $45 \%$ (Koop et al., 2000), many kinds of heterogenous ice nuclei allow ice generation at lower supersaturation thresholds (see e.g. DeMott et al., 2003; Möhler et al., 2006). However, suitable ice nuclei are rare in the upper troposphere, so that it is generally believed that homogeneous nucleation is the dominant pathway for formation of cold cirrus clouds (Sassen and Dodd, 1989; Heymsfield and Sabin, 1989; Kärcher and Ström, 2003). While this may be so, simulations indicate that heterogeneous nucleation can influence the formation of cirrus clouds significantly (Sassen and Benson, 2000; Khvorostyanov and Curry, 2005; DeMott et al., 1997). Box model studies (Gierens, 2003; Ren and Mackenzie, 2005; Liu and Penner, 2005) even suggest that heterogeneous nucleation can suppress homogeneous nucleation if enough heterogeneous ice nuclei are available, depending on environmental conditions, and if the vertical velocity is sufficiently small. Of course, the box model results might be extreme in a sense, because sedimentation is not represented and both nucleation mechanisms are assumed to occur in the same air parcel. This might be different in an extended cirrus cloud, which is the reason that we intend to study the competition of the two ice formation mechanisms in a cloud resolving model.

For that purpose we use the recently developed ice microphysics scheme (Spichtinger and Gierens, 2009a) within the framework of the anelastic non-hydrostatic model EULAG to investigate the competition of two different nucleation processes within the same environment. The present paper is intended to be a process study, hence we perform

Published by Copernicus Publications on behalf of the European Geosciences Union. 
simulations of idealistic cases, which nevertheless are representative for mid latitude cirrus cloud formation. A similar study by Khvorostyanov et al. (2006) was focussed on thin tropical cirrus clouds.

The article is structured as follows: In Sect. 2 we briefly describe our model, for more details we refer to Part 1a. In Sect. 3 we present the general setup for our simulations. Results of reference cases and sensitivity studies are presented and discussed in Sect. 4. Finally, conclusions are drawn in Sect. 5.

\section{Model description}

We now briefly describe the model used in this study, for details we refer to Part 1a and the quoted references. We use the anelastic non-hydrostatic model EULAG (see e.g. Smolarkiewicz and Margolin, 1997); the dry anelastic equations solved in the model are presented in Smolarkiewicz et al. (2001); Grabowski and Smolarkiewicz (2002) and Part 1a. For coupling the dry equations with the ice microphysics, i.e. the moist thermodynamics, we use the concept of the density potential temperature see e.g. Emanuel (1994); Grabowski and Smolarkiewicz (2002) and Part 1a. This leads to new equations (Eqs. 5 and 6 in Part 1a) which are solved by the model.

We use a two-moment bulk microphysics scheme, i.e. number and mass concentrations are prognostic variables. Crystal masses (and sizes) are assumed to obey lognormal distributions with temporally varying mean mass and width. Crystal shapes are droxtals (aspect ratio 1) up to a diameter of $7.42 \mu \mathrm{m}$ and columns with size dependent aspect ratio for larger sizes. An arbitrary number of ice classes can be treated by the scheme. Each ice class is assigned to an aerosol type that nucleates the ice class, hence ice classes are distinguished by their formation mechanism (e.g. heterogeneously vs. homogeneously formed ice). The aerosol types are described by their number and mass concentration as well.

The following processes for cold cirrus clouds are parameterized in our ice microphysics: nucleation (homogeneous/heterogeneous), diffusional growth/evaporation, and sedimentation. We have not included aggregation of ice crystals yet, which is a process of minor importance in cold cirrus clouds $\left(T<-38^{\circ} \mathrm{C}\right)$ where small ice crystals with low terminal velocities predominate (Kajikawa and Heymsfield, 1989). For the parameterisation of homogeneous freezing of aqueous solution droplets we assume sulphuric acid solution droplets as the background aerosol with lognormally distributed mass of the acid (the water content is computed with the Koehler equation). Freezing rates are calculated using the water activity based, temperature dependent parametrization of Koop et al. (2000). Heterogeneous nucleation needs the presence of solid particle surfaces on which the ice germs can form. There are a number of different mechanisms, but for our purpose these details are unimportant, since our question is: what happens to homogeneous nucleation and the cloud evolution when a number of ice crystals is already formed by any mechanism at a lower relative humidity threshold. For this purpose we can apply a very simple parameterisation: We assume that there is a special aerosol type that nucleates into ice at a certain relative humidity $\mathrm{RHi}_{\text {het }}$, that is, at $\mathrm{RHi}_{\text {het }}$ all particles of that aerosol type become ice crystals of the corresponding class. Eventually, upon evaporation of these crystals the aerosol particles are released back to the atmosphere. In principle we can prescribe any form of heterogeneous nucleation behaviour. But any other than a simple threshold would introduce more degrees of freedom which would render the interpretation of the results more complicated. Therefore, for the present paper we do not intend to investigate more complex heterogeneous nucleation behaviour.

For parameterising the diffusional growth or evaporation of single ice crystals we use a modified Koenig ansatz (Koenig, 1971) with corrections for small crystals and ventilation. We assume a mass deposition coefficient of 0.5 for all crystal classes. The new approximation depending on ice crystal mass, temperature and pressure only, allows us to determine the growth rate very accurately without solving the growth equation. This approach is applied to the bulk variable, i.e. the ice water content. For the evaporation of ice crystals, both the ice mass concentration and number concentration decrease in relative proportion as described in Part 1a. To simulate sedimentation we use mass and number weighted terminal velocities, respectively, with parameterisations for single crystals from Heymsfield and Iaquinta (2000).

\section{Setup}

We use the following setup for our simulations: The whole 2-D model domain $(0 \leq x \leq 6.3 \mathrm{~km}, 4 \leq z \leq 13 \mathrm{~km})$ is lifted up adiabatically with a constant updraught velocity $w$ which is equivalent to a constant cooling rate $d T / d t$ for the background temperature profile $T_{e}$. For the reference case we use $w=0.06 \mathrm{~m} \mathrm{~s}^{-1}$, for sensitivity studies we set this variable to $w=0.04,0.08 \mathrm{~m} \mathrm{~s}^{-1}$. We use a horizontal resolution of $\Delta x=100 \mathrm{~m}$ with a horizontal extension of $6.3 \mathrm{~km}$, cyclic boundary conditions in $\mathrm{x}$-direction, a vertical resolution of $\Delta z=10 \mathrm{~m}$ and a dynamical timestep of $\Delta t=1 \mathrm{~s}$. According to our findings in Part 1a this time step is sufficient because of the small vertical velocities. The total simulation time is $t_{s}=300 \mathrm{~min}$ for all simulations which is at the lower end of the synoptic range. The maximum vertical uplift of a layer in our simulation would be $\Delta z=5.3600 \mathrm{~s} \cdot 0.08 \mathrm{~m} \mathrm{~s}^{-1}=1440 \mathrm{~m}$ which is a reasonable value comparable to the typical uplift, e.g. in a warm conveyor belt (see e.g. Spichtinger et al., 2005).

We investigate the competition of different nucleation mechanisms by assuming two classes of ice, one formed by 

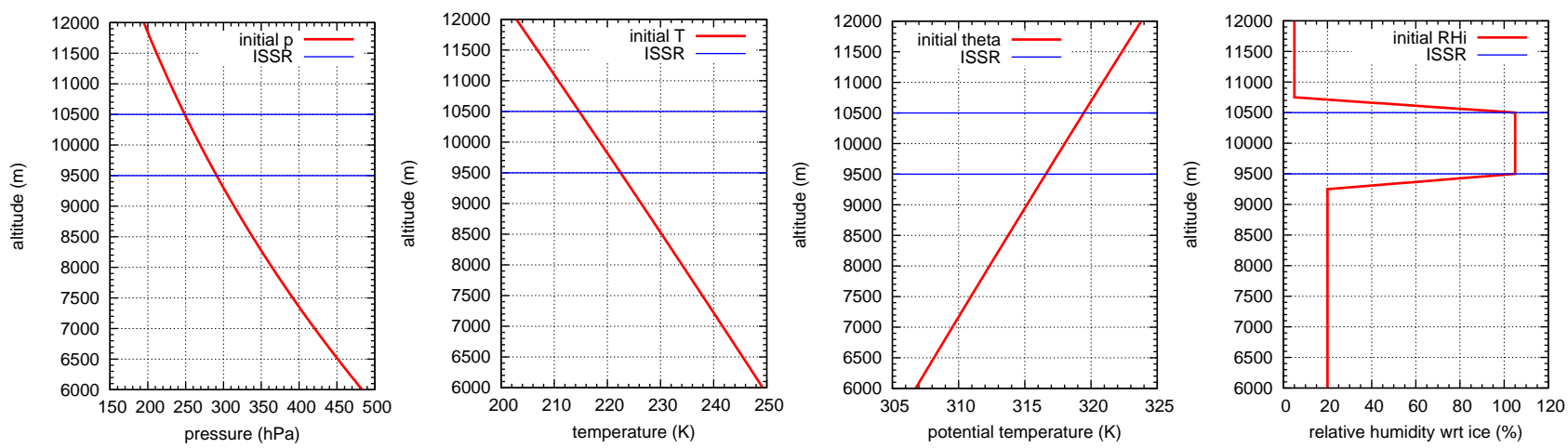

Fig. 1. Initial vertical profiles for the reference case of pressure, temperature, potential temperature and relative humidity with respect to ice (from left to right).

homogeneous nucleation (class 1) and one formed by heterogeneous nucleation (class 2). The background aerosol of class 1, sulphuric acid solution, is assumed to have a lognormal size distribution (size of the pure acid when it would form a sphere) with a geometrical standard deviation of $\sigma_{r}=1.4$, a geometric mean radius of $r_{a}=25 \mathrm{~nm}$ and a number concentration of $n_{a, 1}=N_{a, 1} \rho=300 \mathrm{~cm}^{-3}$. For all simulations in this study we use this setup for the aerosol of class 1 .

The background aerosol of class 2 varies by number concentration and by its threshold supersaturation for ice initiation since these are the ingredients of our sensitivity studies. Since all aerosol particles form ice at one and the same RHi, their size distribution is not specified for these simulations. New ice crystals are assumed to have initial mass of $m=10^{-15} \mathrm{~kg}$, which is equivalent to an initial diameter of $L=D=1.2 \mu \mathrm{m}$. We vary the IN number concentrations in the range $n_{a, 2}=0 / 2 / 5 / 8 / 10 / 20 / 50 \mathrm{~L}^{-1}$. The relative humidity threshold is set to $\mathrm{RHi}_{\text {het }}=130 \%$ in the reference case; sensitivity studies will be performed with thresholds $110 \leq \mathrm{RHi}_{\text {het }} \leq 140 \%$.

In Fig. 1 the initial vertical profiles of the meteorological variables for the reference simulation are shown.

The vertical profiles of potential temperature have been determined by Clark and Farley (1984) such that a constant Brunt-Vaisala frequency of $N=0.0094 \mathrm{~s}^{-1}$ results for the whole model domain; this results into an almost linear temperature profile. The initial vertical profiles of pressure, temperature and potential temperature are the same for all simulations. In the upper part of the model domain we prescribe an ice supersaturated region (ISSR, Gierens et al., 1999) with $\mathrm{RHi}=105 \%$ and a vertical depth of $\Delta z=1 \mathrm{~km}$. This depth is on the lower end of typical vertical extensions for cirrus clouds (see e.g. Mace et al., 2006) but is still in the typical range for an extratropical cirrus cloud and an ice supersaturated layer (Spichtinger et al., 2003). For the reference cases the layer is located between $9.5 \mathrm{~km}$ and $10.5 \mathrm{~km}$, while for sensitivity studies we also consider a higher $\left(10.5 \leq z_{\operatorname{ISSR}} \leq 11.5 \mathrm{~km}\right)$, hence colder, and a lower, hence warmer, layer $\left(8.5 \leq z_{\mathrm{ISSR}} \leq 9.5 \mathrm{~km}\right)$.

\section{Discussion of results}

We first describe the results of the reference cases, which have constant vertical updraught of $w=0.06 \mathrm{~m} \mathrm{~s}^{-1}$ without fluctuations (making the simulation quasi 1-D). The ISSR initially covers the vertical range $9500 \leq z \leq 10500 \mathrm{~m}$. The background aerosol concentration (heterogeneous IN) is varied in the range $n_{a, 2}=0 / 2 / 5 / 8 / 10 / 20 / 50 \mathrm{~L}^{-1}$. Then we study several sensitivities, e.g. using ISSRs at different altitudes or temperatures (Sect. 4.4), using different updraught velocities (Sect. 4.3), using different thresholds for heterogeneous nucleation (Sect. 4.2) and finally using full 2-D simulations with temperature (and velocity) fluctuations superimposed (Sect. 4.5).

\subsection{Reference experiments}

Figure 2 shows the evolution of a cirrus cloud when it is unaffected by heterogeneous ice nuclei, that is, when only homogeneous nucleation occurs.

The cloud appears almost simultaneously throughout the depth of the ISSR at $t_{s} \sim 100 \mathrm{~min}$. Due to the growth of the ice crystals excess vapour within the cloud is consumed quickly, and the supersaturation gets reduced close to saturation at about $t_{s}=130 \mathrm{~min}$. Sedimentation together with the ongoing cooling leads to persistent supersaturation at the upper edge of the cirrus which periodically becomes high enough to trigger another nucleation pulse (cf. Part 1a). The falling ice crystals formed in the permanent nucleation zone at cloud top act as an efficient sink for water vapour in the lower cloud regions, where in spite of the ongoing cooling the relative humidity is maintained at saturation due to the growth of the falling ice crystals. 


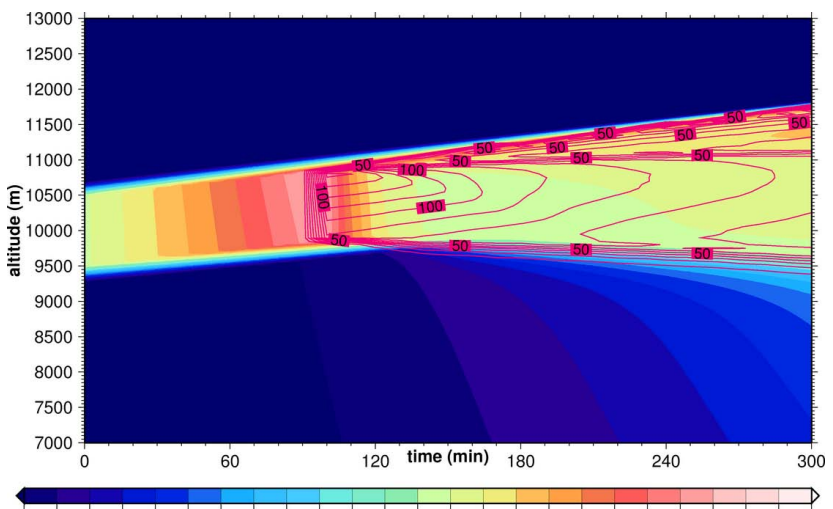

$28 \quad 34 \quad 40 \quad 46 \quad 5258 \quad 64 \quad 7076 \quad 8288 \quad 94100106112118124130136142148154160166172$ $\mathrm{RHi}(\%)$

Fig. 2. Time evolution of the relative humidity wrt ice and ice crystal number densities (purple isolines, in $10 \mathrm{~L}^{-1}$ steps) in the reference cirrus with $w=0.06 \mathrm{~m} \mathrm{~s}^{-1}$ and only homogeneous nucleation.

When heterogeneous ice nuclei are present in the ISSR, cloud evolution changes significantly. Now, the first crystals form by heterogeneous nucleation at $t_{s} \sim 60 \mathrm{~min}$. These ice crystals find a highly supersaturated environment with much less competition for the excess vapour than ice crystals formed homogeneously, because of the low number concentration of IN. Thus they rapidly grow and start to fall which causes a vertical concentration gradient of ice in the ISSR, i.e. more ice at ISSR base than at its top. Thus the rate at which excess vapour is consumed due to ice growth decreases with altitude in the ISSR and the originally rectangular humidity profile gets more and more tilted with values increasing with altitude before homogeneous nucleation sets in. The tilting is additionally supported by the temperature dependent growth of ice crystals. The change of the RHi profile is the stronger the more IN are present (see Fig. 3) and it affects the homogeneous nucleation event and the later cloud evolution. While homogeneous nucleation takes place over the whole depth of the ISSR when no IN are present, the inclusion of more and more IN confines the region where homogeneous nucleation can occur more and more to the cloud top.

Figure 4 shows the evolution of the cloud with varying numbers of IN; it can be compared to Fig. 2 which shows the case without IN. An IN number concentration of $n_{a, 2}=5 \mathrm{~L}^{-1}$ does not yet affect much the structure of the cirrus; the heterogeneously formed ice crystals are not sufficient to halt the increase of supersaturation within the cloud. Hence homogeneous nucleation still occurs throughout the supersaturated layer, but with a delay of about $30 \mathrm{~min}$ between cloud top and base, as explained above. Enough ice crystals form homogeneously to reduce the relative humidity almost to saturation. The steady state relative humidity wrt ice inside the cloud at $t_{s}=180 \mathrm{~min}$ is slightly higher $(\sim 110 \%)$ in this case than in the case without heterogeneous ice nuclei $(\sim 105 \%)$, because slightly less ice crystals are produced (homogeneously) in

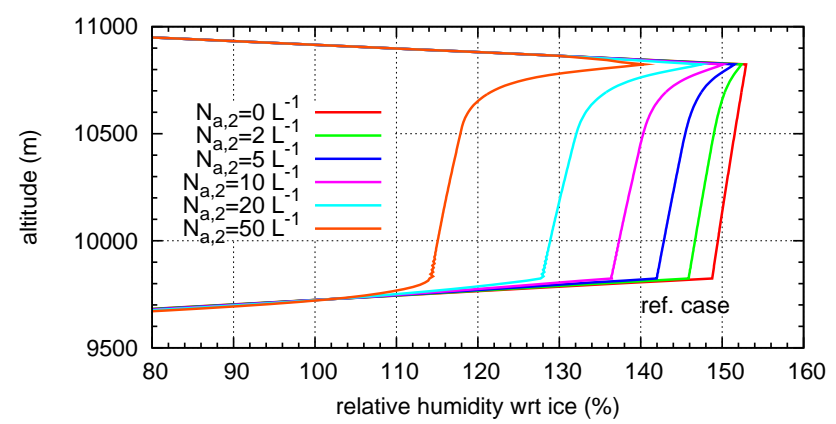

Fig. 3. Modification of the RHi profile due to different ice nuclei concentrations at simulation time $t=90 \mathrm{~min}$ (just before homogeneous nucleation starts).

this case than in the case without IN. The slight reduction of the number of homogeneously formed crystals is a consequence of the reduced rate at which supersaturation increases at the nucleation threshold. This implies a smaller overshooting of RHi over the threshold, hence less ice crystals. (Although the notion overshooting implies the whole $\mathrm{RHi}(t)$ during the period when $\mathrm{RHi}>\mathrm{RHi}_{\text {hom }}$, the main effect on the number of ice crystals produced is that the peak supersaturation is reduced when the overshooting is weaker).

By further increasing the IN concentration to $10 \mathrm{~L}^{-1}$, more ice crystals are formed heterogeneously which consume more vapour than in the preceeding case. Accordingly, the rate at which supersaturation increases further in the cloud is lower than before, such that the overshooting over the homogeneous threshold is flattened, and homogeneous nucleation produces less crystals. Because the concentration of heterogeneously formed crystals increases with depth in the cloud due to sedimentation, the increase of supersaturation in the lower half of the cloud is inhibited so much that the threshold for homogeneous freezing is not reached anymore. Hence homogeneous nucleation is confined to the upper half of the cloud. Although the concentration of heterogeneous ice crystals is high enough to inhibit homogeneous nucleation in the lower part of the cloud, it is not sufficient to deplete the excess vapour down to saturation at the cloud bottom, also because these crystals quickly fall out of the supersaturated layer. In contrast, homogeneous nucleation in the upper cloud part still produces a sufficient number of crystals that effectively use up the excess vapour. Hence the cloud obtains a two-layer structure with high ice number density and RHi close to saturation in the upper layer and low ice number density but persistent supersaturation in the lower layer. The persistent supersaturation is only depleted later (after, say, 4h) when enough homogeneously formed ice crystals have fallen into the lower layer where they take up the excess vapour.

Progressing to $20 \mathrm{IN} \mathrm{L}^{-1}$, we see that the heterogeneously formed ice crystals start to deplete the supersaturation in the 
lower cloud layer while persistent supersaturation is maintained over almost the remaining cloud depth. Only at the uppermost cloud top homogeneous nucleation is possible but too few crystals are produced to effectively reduce the supersaturation. On further increasing the IN concentration the bottom layer of the cloud where the heterogeneous ice crystals deplete the excess vapour down to saturation becomes thicker, but there is still a layer of persistent supersaturation at the top of the cloud which gets deeper over time as the heterogeneously formed ice crystals sediment down while the ongoing updraught leads to further cooling. In summary, there are three different regimes:

1. Only few heterogeneous IN (up to about $10 \mathrm{~L}^{-1}$ ): Homogeneous nucleation occurs over the whole depth of the cloud, i.e. nucleation and depositional growth determines the structure of the cirrus cloud.

2. Medium number of IN (about $10 \mathrm{~L}^{-1}$ ): Heterogeneously formed ice crystals begin to significantly affect the cirrus cloud. Homogeneous nucleation is confined to a more and more shallow layer at cloud top, yet still a sufficient number of ice crystals are formed there that effectively reduce supersaturation in the upper cloud part. In the lower cloud part, heterogeneously formed crystals inhibit homogeneous nucleation while they are not yet sufficient in number to reduce the supersaturation. A zone with long lasting or persistent supersaturation is thus present in the lower cloud part.

3. Large number of IN ( $20 \mathrm{~L}^{-1}$ and more): The cloud is completely dominated by heterogeneously formed ice, which is sufficient in number to relax the supersaturation in the lower part of the cloud down to saturation. When cooling goes on for hours, supersaturation can build up again in the upper part of the cloud after enough ice crystals have fallen down due to gravity. This may still later lead to relatively undisturbed homogeneous nucleation.

The transition between predominantly homogeneous and heterogeneous ice formation occurs at about $10 \mathrm{INL}^{-1}$; the same value is predicted by the analytical formula Eq. (21) of Gierens (2003), when $216 \mathrm{~K}$ and $260 \mathrm{hPa}$ are used as mean temperature and pressure in the cloud after $1 \mathrm{~h}$ of uplift. It can be seen that high supersaturation inside cirrus clouds (not considering the one at cloud top) can be maintained over a long period when IN are present and when steady cooling goes on over several hours. The supersaturation zone is in the lower part of the cloud when low to medium number concentration of IN is present, while it shifts to the upper part of the cloud when the IN concentration is high.
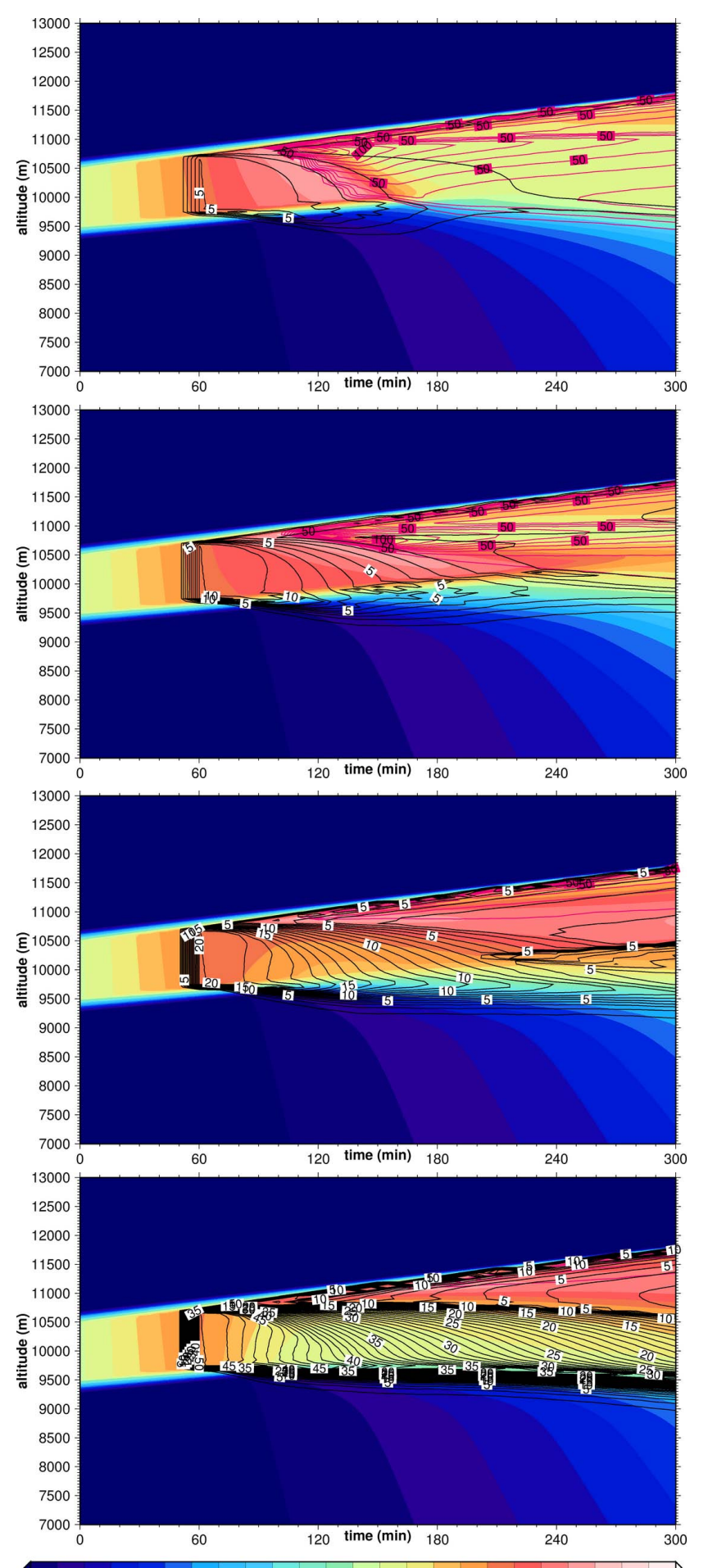

$28 \quad 3440 \quad 46 \quad 5258 \quad 64 \quad 70 \quad 76 \quad 828894 \quad 100106112118124130136142148154160166172$ $\mathrm{RHi}(\%)$

Fig. 4. Time evolution of the relative humidity wrt ice and ice crystal number densities (heterogeneously nucleated crystals: black isolines, in $1 \mathrm{~L}^{-1}$ steps, homogeneously nucleated crystals: purple isolines in $10 \mathrm{~L}^{-1}$ steps) in the reference cirrus with $w=0.06 \mathrm{~m} \mathrm{~s}^{-1}$ and varying heterogeneous IN concentrations $\left(n_{a, 2}=5 / 10 / 20 / 50 \mathrm{~L}^{-1}\right)$ from top to bottom. 

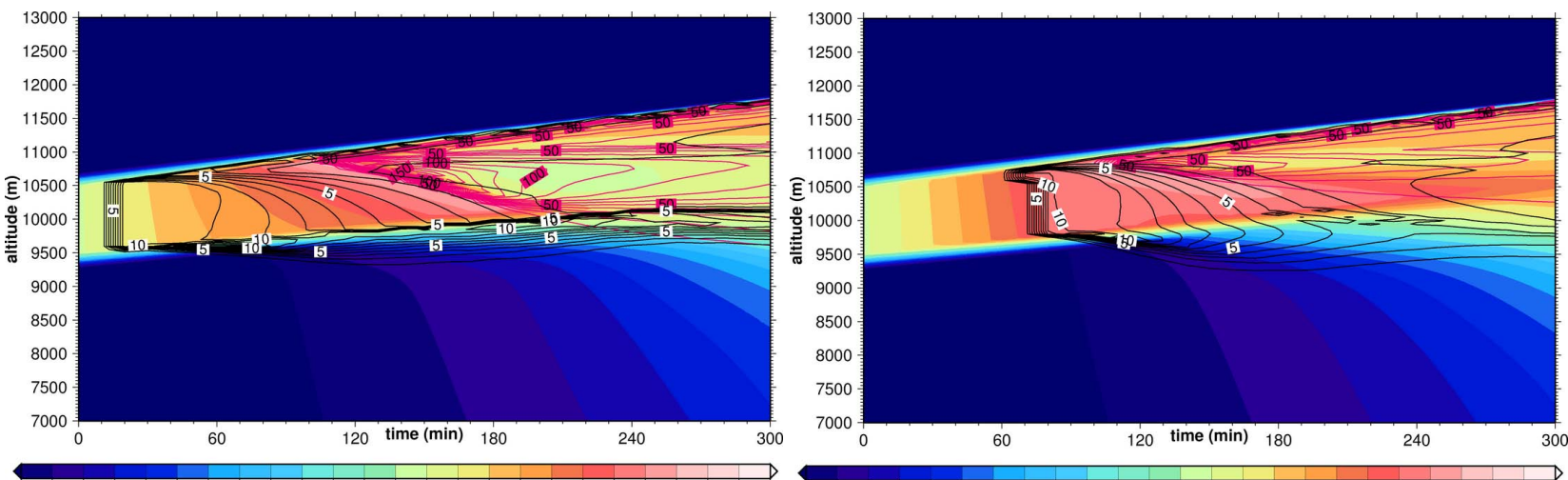

$283440465258 \quad 647076 \quad 82 \quad 8894 \quad 100106112118124130136142148154160166172 \quad 28 \quad 34 \quad 40 \quad 46 \quad 52 \quad 58 \quad 6470 \quad 76 \quad 82 \quad 88 \quad 94 \quad 100106112118124130136142148154160166172$ $\mathrm{RHi}(\%)$ 

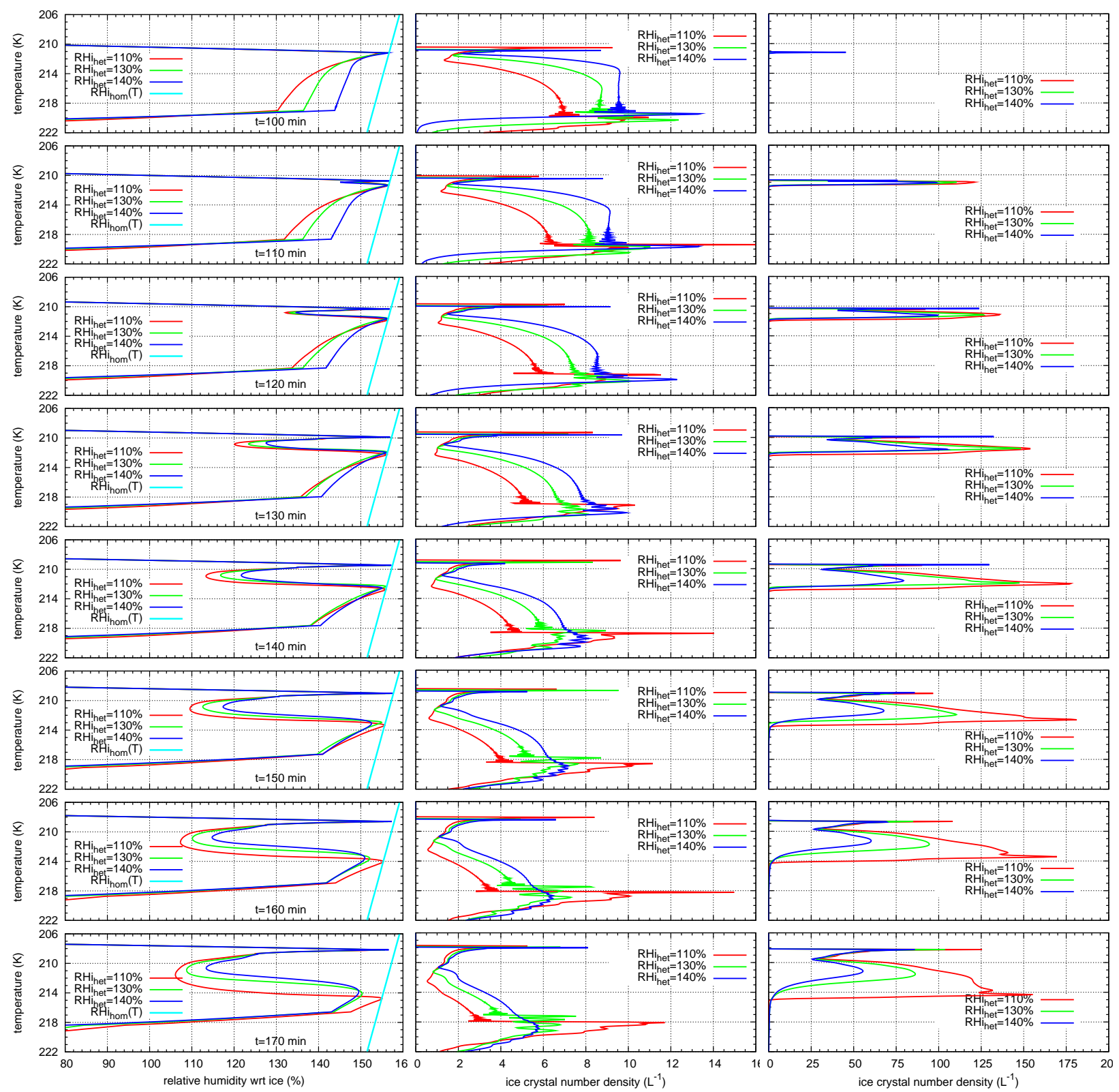

Fig. 6. Vertical profiles of relative humidity wrt ice (in $\%$, left), heterogeneously formed ice crystal number density (in $\mathrm{L}^{-1}$, middle) and homogeneously nucleated ice crystal number density (in $\mathrm{L}^{-1}$, right), respectively, versus temperature for simulation times $t_{s}=100,110,120,130,140,150,160,170 \mathrm{~min}$ (from top to bottom). The light blue line in the left hand panels is the temperature dependent threshold for homogeneous nucleation of solution droplets of size $0.25 \mu \mathrm{m}$, expressed as $R H i_{\text {hom }}=100 \%(2.583-T / 207.83 \mathrm{~K})$.

ISSR and persistent supersaturation (below the homogeneous threshold) can be maintained there. Since homogeneous nucleation occurs over the full ISSR depth in the case with $\mathrm{RHi}_{\text {het }}=110 \%$, supersaturation becomes reduced throughout the ISSR (except the top level) in that case, but not the others.

\subsection{Variation of the uplift speed}

The uplift speed, $w$, or cooling rate, has two important influences on a cirrus cloud. First, the number of ice crystals that form homogeneously when no IN are present, scales approximately as $w^{3 / 2}$ (Kärcher and Lohmann, 2002). Second, the critical IN concentration of Gierens (2003) scales as $w^{3 / 2}$, as well. In our sensitivity study we use values of 
$w=0.04 \mathrm{~m} \mathrm{~s}^{-1}$ and $w=0.08 \mathrm{~m} \mathrm{~s}^{-1}$, respectively, both typical synoptic values. As we have seen in Part 1a, even variation in this restricted range affects the structure of the simulated cirrus clouds considerably. Over this range, $w^{3 / 2}$ changes by a factor of 2.8. The critical IN concentrations are 4.5 and $13 \mathrm{~L}^{-1}$, respectively.

Theoretical considerations (e.g. Gierens, 2003) show that the influence of heterogeneously formed ice crystals on the further evolution of a cirrus cloud decreases with increasing uplift strength. When the uplift is strong enough, homogeneous nucleation will occur for sure, and produce much more ice crystals than heterogeneous nucleation has produced before. The stronger the uplift, the more crystals are produced homogeneously while the number of heterogeneously formed crystals does not depend on uplift strength. Hence the further evolution of the cloud in all respects is less and less affected by the presence of a smaller and smaller portion of heterogeneously formed crystals with increasing uplift strength. This is indeed what we find here.

Comparing the time evolution for low and high vertical windspeed (Fig. 7 left and right, respectively) with the time evolution in the reference case (Figs. 2 and 4) shows that the case with highest $w$ and lowest IN concentration experiences a similar homogeneous nucleation event like the pure homogeneous case. For instance, homogeneous nucleation takes place almost simultaneously over the whole depth of the ISSR, in spite of the presence of the heterogeneously formed ice crystals. The cooling rate is sufficiently high to overcome the depletion of the excess vapour by the growth of the heterogeneous ice. For the case with $w=0.04 \mathrm{~m} \mathrm{~s}^{-1}$ and the low IN concentration of $5 \mathrm{~L}^{-1}$ the formula of Gierens (2003) predicts inhibition of homogeneous nucleation which, however, happens over the complete depth of the cloud. The reason is that the slow uplift allows the heterogeneous crystals to fall out of the cloud before the humidity reaches the homogeneous nucleation threshold. Sedimentation is, however, not included in the derivation of the formula of Gierens (2003).

At $w=0.08 \mathrm{~m} \mathrm{~s}^{-1}, 10 \mathrm{IN} \mathrm{L}^{-1}$ are still not sufficient to hinder homogeneous nucleation to occur over the whole depth of the cloud. The cloud quickly reaches ice saturation after the homogeneous nucleation event. However, at $w=0.04 \mathrm{~m} \mathrm{~s}^{-1}$ the same concentration of IN shuts down homogeneous nucleation almost completely (apart from the uppermost layer). As before, the concentration of heterogeneously formed crystals is insufficient to reduce the supersaturation, hence we get here a situation where almost the whole cloud depth remains highly supersaturated for the $5 \mathrm{~h}$ simulation time. After about $4 \mathrm{~h}$ the region is essentially free of crystals because they are already fallen out. With higher IN concentrations and slow uplift, the heterogenously formed ice crystals start to consume the supersaturation and the two-layer structure re-appears with low supersaturation in the lower cloud part and high supersaturation in the upper part, as in the corresponding reference cases.
$20 \mathrm{INL}^{-1}$ are required in the stronger uplift case with $w=0.08 \mathrm{~m} \mathrm{~s}^{-1}$, to shut down homogeneous nucleation over most of the cloud depth. However, supersaturation is not effectively removed by the heterogeneously formed crystals, because of the higher cooling rate. Only in the case with $50 \mathrm{INL}^{-1}$ we get an approximately ice-saturated layer at cloud bottom. The upper half is still in a highly supersaturated state after $5 \mathrm{~h}$ simulation time.

The resume of this section is that we still have three regimes of IN concentrations, one where homogeneous nucleation is hardly affected, one where it is almost completely inhibited, and an intermediate one where slight parameter changes can dramatically change the evolution of the cloud structure. As expected, the critical IN concentration increases with uplift speed.

\subsection{Impact of temperature}

So far we described simulations with an initial temperature in the ice supersaturated layer of $215 \leq T \leq 222 \mathrm{~K}$. As homogeneous nucleation rates, depositional growth rates, and the effect of IN on the later cloud evolution depend sensitively on temperature, we now perform simulations with colder and warmer ice supersaturated layers, namely $206 \leq T \leq 215 \mathrm{~K}$ and $222 \leq T \leq 230 \mathrm{~K}$, respectively. These temperature variations are realised simply by shifting the ISSR up and down $1 \mathrm{~km}$. For the critical IN concentrations we find $6.5 \mathrm{~L}^{-1}$ for the warm case (assuming $224 \mathrm{~K}$ and $300 \mathrm{hPa}$ ) and $16 \mathrm{~L}^{-1}$ for the cold case $(209 \mathrm{~K}, 200 \mathrm{hPa})$. The changes are mostly due to the temperature dependence of homogeneous nucleation rates and deposition growth rates (see Part 1a).

The temperature effect on homogeneous nucleation can be seen in Fig. 8 which shows cases without IN, i.e. the result of purely homogeneous nucleation, just after cloud formation at $t_{s} \sim 100 \mathrm{~min}$. Without IN, homogeneous nucleation occurs in all $T$-ranges almost simultaneously throughout the ISSR.

In the warm case, $5 \mathrm{IN} \mathrm{L}^{-1}$ are not sufficient to inhibit homogeneous nucleation anywhere in the ISSR, hence the latter happens over the whole depth of the cloud layer. However, $d S i / d t$ is retarded by the few heterogenous ice crystals such that less ice crystals are produced homogeneously. Later (after about $3 \mathrm{~h}$ ) this has the effect of leaving a persistent supersaturated layer in the upper part of the cloud when due to sedimentation too little ice crystals remain there to effectively take up the excess vapour. In the simulations we have discussed so far, the crystals leaving this layer were always replaced by fresh crystals falling from cloud top, where the ongoing cooling periodically led to new nucleation bursts. In the warm case this effect is much weaker due to the relatively low nucleation rate at this temperature. Less crystals form with less competition for excess vapour. Additionally at higher temperature there is higher absolute humidity. Hence crystals grow quicker and fall faster through the supersaturated layers. Consequently, they have smaller effect there. 

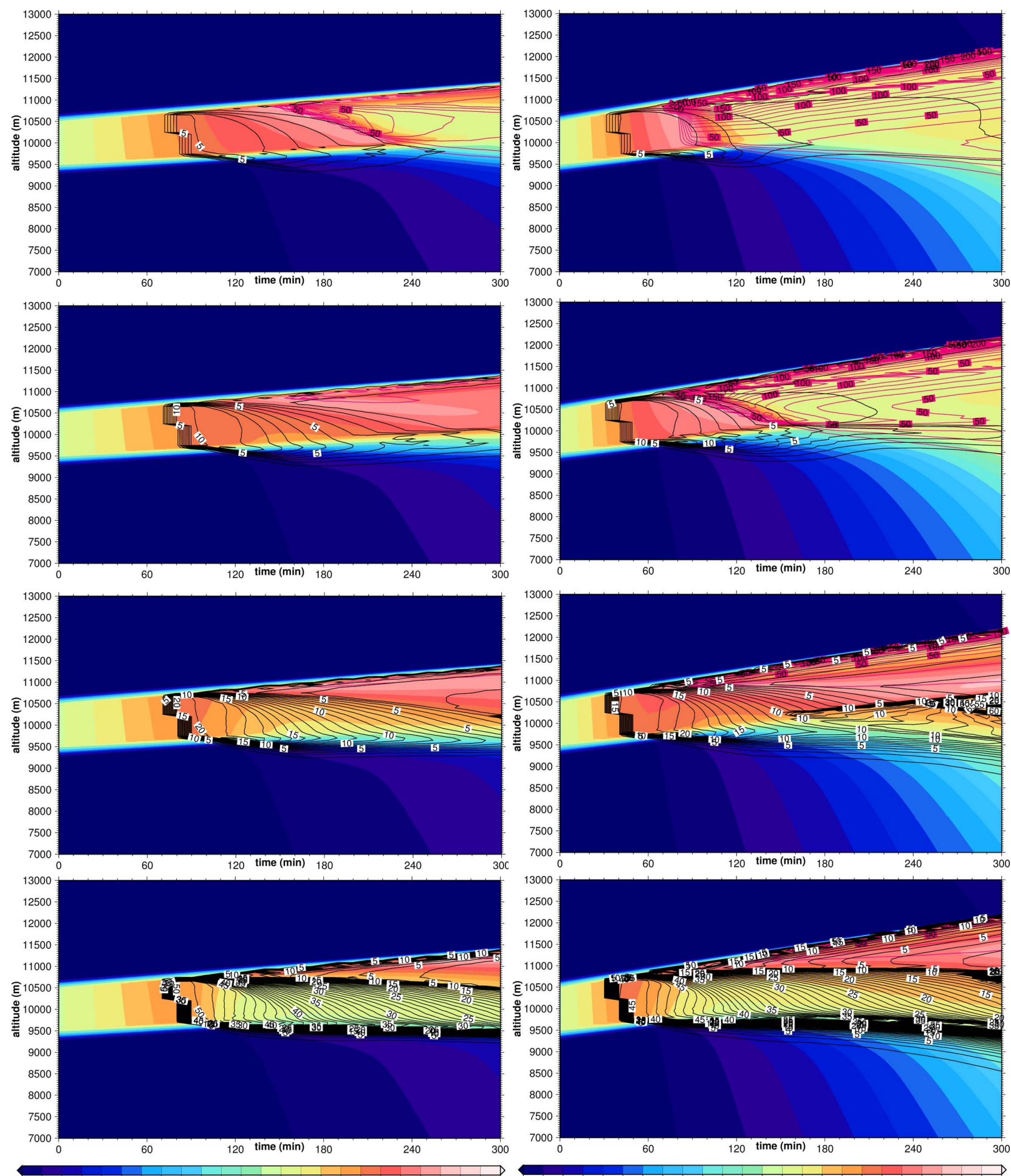

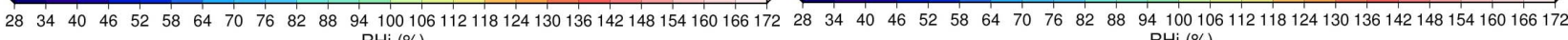
$\mathrm{RHi}(\%)$

Fig. 7. Time evolution of the relative humidity wrt ice and ice crystal number densities (heterogeneously nucleated crystals: black isolines, in $1 \mathrm{~L}^{-1}$ steps, homogeneously nucleated crystals: purple isolines in $10 \mathrm{~L}^{-1}$ steps) in the reference cirrus with $w=0.04 \mathrm{~m} \mathrm{~s}$ (left) and $w=0.08 \mathrm{~m} \mathrm{~s}^{-1}$ (right), respectively, and varying heterogeneous IN concentrations $\left(5 / 10 / 20 / 50 \mathrm{~L}^{-1}\right)$ from top to bottom. 


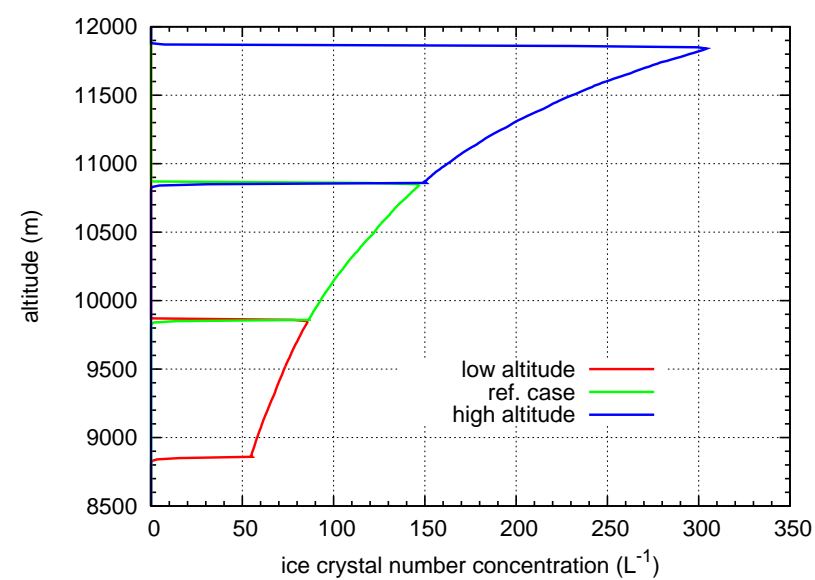

Fig. 8. Ice crystal number densities for cirrus clouds formed at different temperature ranges at simulation time $t_{s}=100 \mathrm{~min}$. Note that the curves are plotted for cases of pure homogeneous nucleation.

As $10 \mathrm{IN} \mathrm{L}^{-1}$ is already significantly above the critical IN concentration in the warm case, we find homogeneous nucleation confined to the uppermost layer of the ISSR, producing only few crystals, such that in-cloud supersaturation is not reduced for hours, until the end of the simulation after $5 \mathrm{~h}$. The supersaturated region at that time is almost void of ice. Even higher IN concentrations shut down homogeneous nucleation nearly completely, and lead to more and more consumption of the excess vapour in the lower parts of the cloud, leaving the 2-layer type cloud as in the simulations before with high IN concentrations. The heterogeneous ice grows faster than in the reference cases, thus its sedimentation fluxes are larger and the lower saturated layer is thinner than in the reference case, while for the upper supersaturated layer it is vice versa.

In the cold case the transition between the predominantly homogeneous and heterogeneous cloud ice formation takes place between the 10 and $20 \mathrm{IN} \mathrm{L}^{-1}$ cases, as expected. Sedimentation fluxes of the heterogeneous ice are small compared to the warm and reference cases, such that in the situation with the highest concentration of IN the lower saturated layer is thicker than in those other cases.

\subsection{Effect of temperature fluctuations}

We have seen in Part 1b (Spichtinger and Gierens, 2009b) that initial temperature fluctuations forming wind field fluctuations (i.e. small eddies) have the effect to reduce mean values of cloud ice and crystal number concentrations and to leave more water in the vapour phase. These results were obtained from simulations with purely homogeneous nucleation. When there are fluctuations a few of the model grid boxes obtain a higher than average cooling rate and these are the first grid boxes where homogeneous nucleation occurs, producing higher than average crystal numbers due to the higher cooling rate. Some of the new crystals are soon transported into the neighbouring, still cloud free, grid boxes by the small eddies that result from the fluctuations. These crystals now reduce $d S i / d t$ in their new grid boxes where thus less than average ice crystals are produced eventually. Now the question arises whether and how the presence of IN and their impact on cloud evolution prior to homogeneous nucleation changes the fluctuation effects.

We do not expect an impact of fluctuations on heterogeneous nucleation because the formulation of this process in our model is not sensitive to them. Once the heterogeneous threshold is surpassed, every IN freezes independently of the rate at which the relative humidity increases beyond the threshold. This kind of insensitivity should not change much with a more sophisticated parameterisation of heterogeneous nucleation unless the number concentrations of heterogeneously formed crystals is large enough that mixing into neighbouring grid boxes has a major effect on $d S i / d t$ there. However, even at our highest IN concentrations we have not seen such an effect.

Considering the temporal evolution of clouds formed predominantly by homogeneous nucleation we find that RHi profiles display extreme variability exceeding $30 \%$ (in units of RHi) during the relaxation phase that follows the homogeneous nucleation event. The RHi fluctuations are smaller $(\approx 10 \%)$ before nucleation starts, and after the relaxation phase they decrease to the roughly $10 \%$ range. The extreme RHi variability during the relaxation phase is a consequence of (a) the high nucleation threshold which marks the upper limit of the fluctuations, (b) the differing starting times for the relaxation process in different grid boxes at the same altitude, and (c) the differing relaxation rates due to the variation in crystal surface area concentration in different grid boxes which in turn result from the different cooling rates. Because of the periodically occuring nucleation bursts at the upper cloud boundary, there are always strong RHi fluctuations in this region. Figure 9 shows this time evolution of the relative humidity fluctuations around the starting point of homogeneous nucleation (around $t \sim 100 \mathrm{~min}$ ).

Clouds that are dominated by heterogeneously formed ice crystals do not display large RHi variability over a large fraction of their development. Typically, RHi variability does not exceed 5\% in any level. Only in the later evolution when the heterogoeneously formed ice has fallen out of much of the cloud and when thus homogeneous nucleation starts to produce larger numbers of ice crystals in the upper part of the cloud, RHi fluctuations get larger. Apart from the crystal growth, the different sedimentation fluxes of homogeneously formed crystals into lower levels with still substantial average supersaturation leads there to stronger RHi variability than before when only the heterogeneously formed crystals were present. The increase of RHi variability must be a consequence of the increasing and spatially highly varying crystal number concentration when the homogeneously formed crystals arrive from above. In Fig. 10 

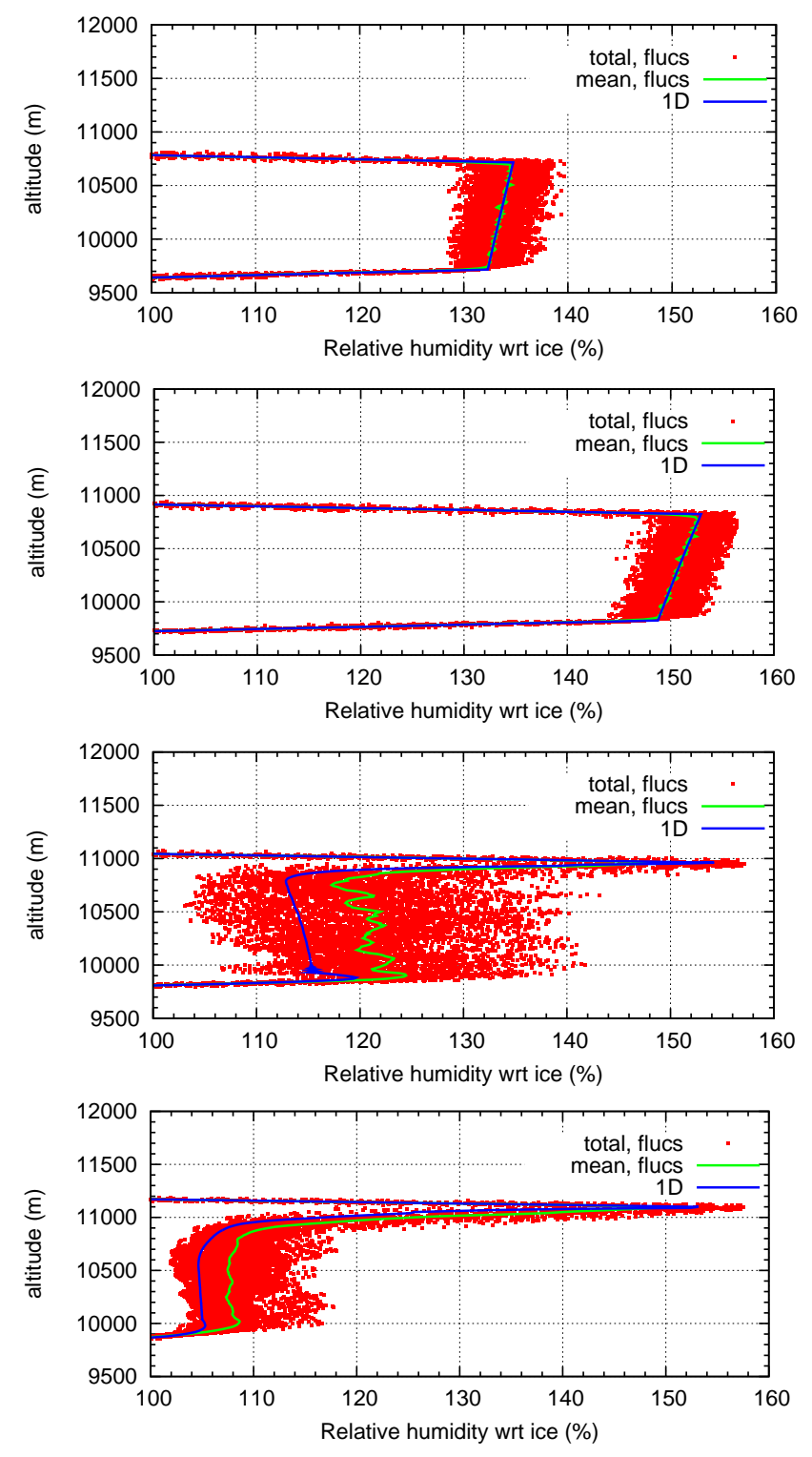

Fig. 9. Time evolution for the relative humidity in the simulation with only homogeneous nucleation. From top to bottom: simulation time $t_{s}=60 / 90 / 120 / 150 \mathrm{~min}$, i.e. around the starting point of homogeneous nucleation.

the time evolution of the variability of relative humidity for the case of $n_{a, 2}=20 \mathrm{~L}^{-1}$ is shown; starting from very small variability at $t_{s}=120 \mathrm{~min}$ an increasing strength of the variations can be observed when homogeneous nucleation begins to dominate the cloud.

Clouds with approximately the critical concentration of IN initially behave like clouds formed predominantly by homogeneous nucleation. In the upper part of the cloud where homogeneous nucleation occurs first we find the typical strong RHi variability during the relaxation phase. The fluctuations first are relatively weak in the lower part of the
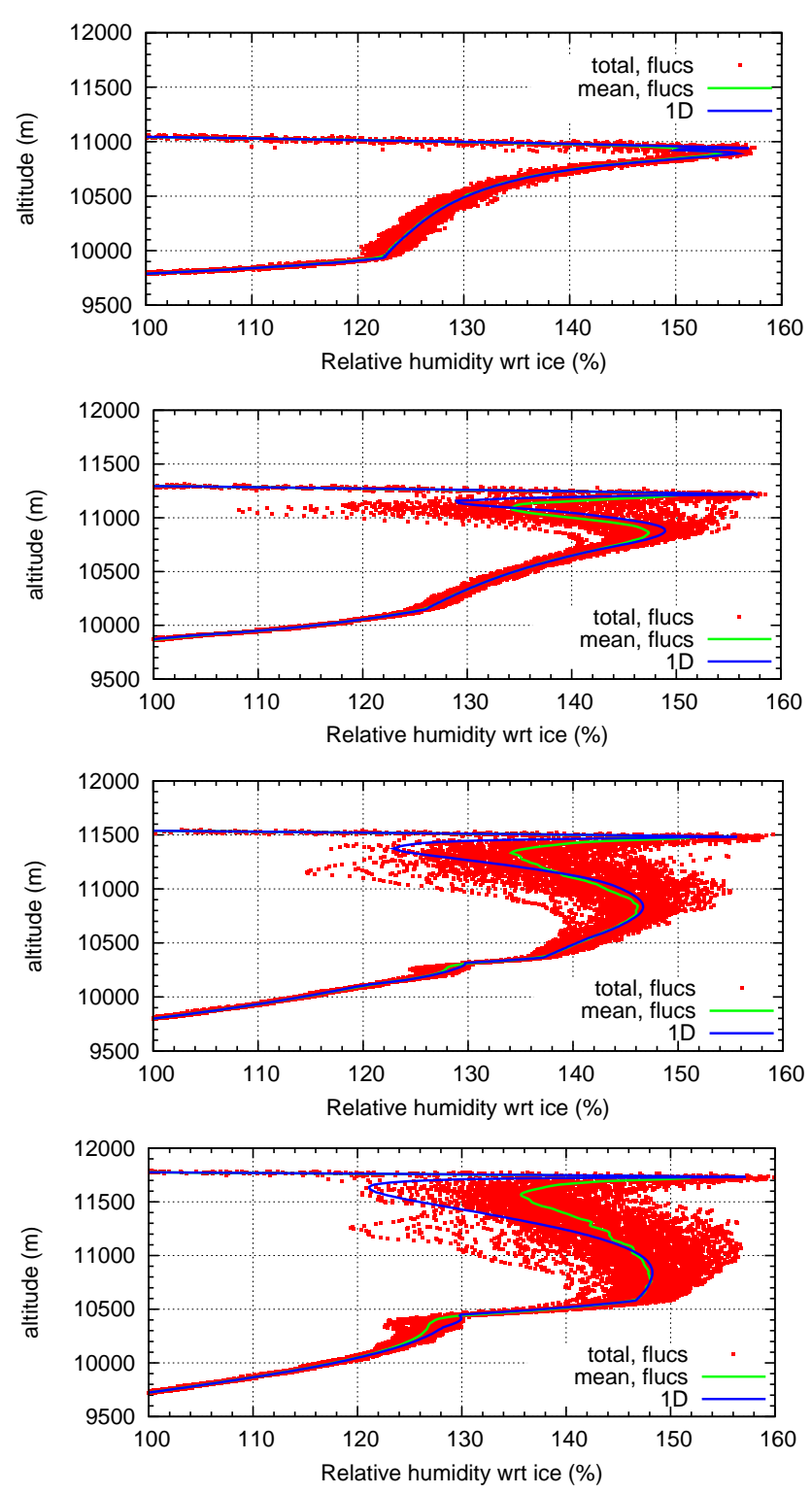

Fig. 10. Time evolution for the relative humidity in the simulation with $n_{a, 2}=20 \mathrm{~L}^{-1}$. From top to bottom: simulation time $t_{s}=120 / 180 / 240 / 300 \mathrm{~min}$.

cloud. However, the supersaturation there is large (albeit below the homogeneous threshold) and lots of homogeneously formed crystals fall into this layer from above where they start to consume the excess vapour. Since the sedimentation flux density fluctuates itself, the vapour take up varies from grid cell to grid cell, leading eventually to large variability in the RHi profiles. Overall, the fluctuation effect on the RHi profiles is largest in the case with critical IN number concentration. In Fig. 11 the time evolution of the relative humidity fluctuations for the case of $n_{a, 2}=10 \mathrm{~L}^{-1}$ is shown. The strong variability of the humidity profiles in this mixed case can be observed clearly. 

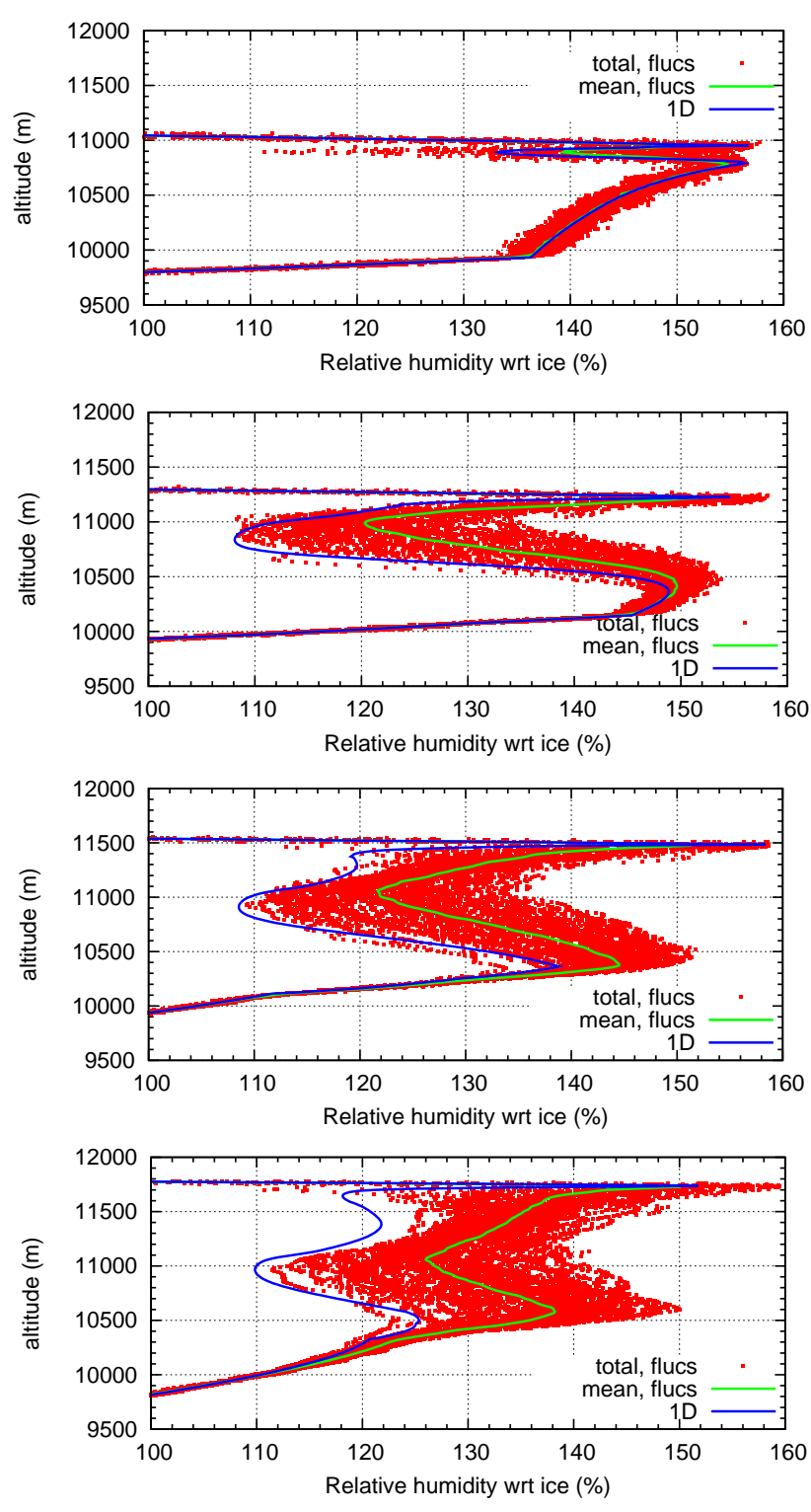

Fig. 11. Time evolution for the relative humidity in the simulation with $n_{a, 2}=10 \mathrm{~L}^{-1}$. From top to bottom: simulation time $t_{s}=120 / 180 / 240 / 300 \mathrm{~min}$.

Finally we show statistics of in-cloud supersaturation, a topic that attracted quite some interest during recent years (e.g. Ovarlez et al., 2002; Korolev and Mazin, 2003; Spichtinger et al., 2004; Peter et al., 2006). We evaluate the humidity fields in an altitude range $10400 \leq z \leq 10600 \mathrm{~m}$ (mimicking aircraft probing) for a couple of simulation times (i.e. cloud ages) and for IN concentrations from zero to $50 \mathrm{~L}^{-1}$. The frequency distributions are shown in Fig. 12. As we can see, a cloud that forms predominantly by either type of nucleation, homogeneous or heterogeneous, sooner or later approaches saturation, that is the humidity distri- bution centres around a quasi-steady supersaturation value (Korolev and Mazin, 2003) at about 110\% RHi. In contrast, clouds where neither nucleation process dominates display long-lasting significant in-cloud supersaturation exceeding $130 \% \mathrm{RHi}$, in particular when the critical IN concentration is present. Of course, the persistent supersaturation is the consequence of the ongoing uplift and the relatively low ice crystal concentration in some regions of the cloud, which in turn is due to the attenuation of homogeneous nucleation caused by the pre-existing heterogeneously formed ice. These results show that long-lasting in-cloud supersaturation can be explained by dynamics and standard microphysics alone; there is no need to resort to exotic phenomena (for instance cubic ice formation at $T<200 \mathrm{~K}$ (Murray et al., 2005; Murray, 2008a), suppressing homogeneous nucleation via organic compounds (Kärcher and Koop, 2005), glassy states of aqueous solutions that inhibit freezing (Zobrist et al., 2008; Murray, 2008b) ) for an explanation, although they are not excluded and could contribute to the phenomenon, perhaps in a more pronounced way at temperatures $T<200 \mathrm{~K}$.

\subsection{Cloud effects on background aerosol distribution}

All our simulations were initialised with a uniform homogeneous background distribution of IN, clearly an idealisation. These IN form ice crystals that in turn grow, fall to cloud base and below into the subsaturated sub-cloud layer and eventually evaporate, thereby giving back the IN to the background atmosphere. Since the IN do not fall, they become enriched in a layer below the cloud. The enrichment factor can be quite large. For instance, when the initial background concentrations was $n_{a, 2}=20 \mathrm{~L}^{-1}$, the sub-cloud enrichment leads to values of $n_{a, 2}=70-80 \mathrm{~L}^{-1}$ in the simulations. In real situations the enrichment would of course also depend on the humidity profile below the cloud which controls the evaporation rate of the ice crystals. The high enrichment factor here stems from the sharp humidity gradient below the ISSR which leads to quick evaporation over a short falling distance.

The assumed ongoing cooling sooner or later leads to high humidity values also in the sub-cloud layer. The previously evaporated ice adds further to the humidity increase, such that eventually the threshold for heterogeneous nucleation is reached and surpassed again. Hence a new cloud of heterogeneous ice may form just below the original cloud, and even partly within the old cloud, since the falling homogeneous ice crystals may already have reached this layer as well. In Fig. 13 the heterogeneous formation of ice crystals in this sub cloud layer with enriched IN concentrations is shown for two example simulations (top: $w=0.06 \mathrm{~m} \mathrm{~s}^{-1}$, ISSR in low temperature regime; bottom: $w=0.08 \mathrm{~m} \mathrm{~s}^{-1}$, ISSR in reference temperature regime). In both cases, the layer structure of the heterogeneously formed cirrus clouds resembles the enrichment of the scavenged aerosols in a thin sub-cloud layer. 

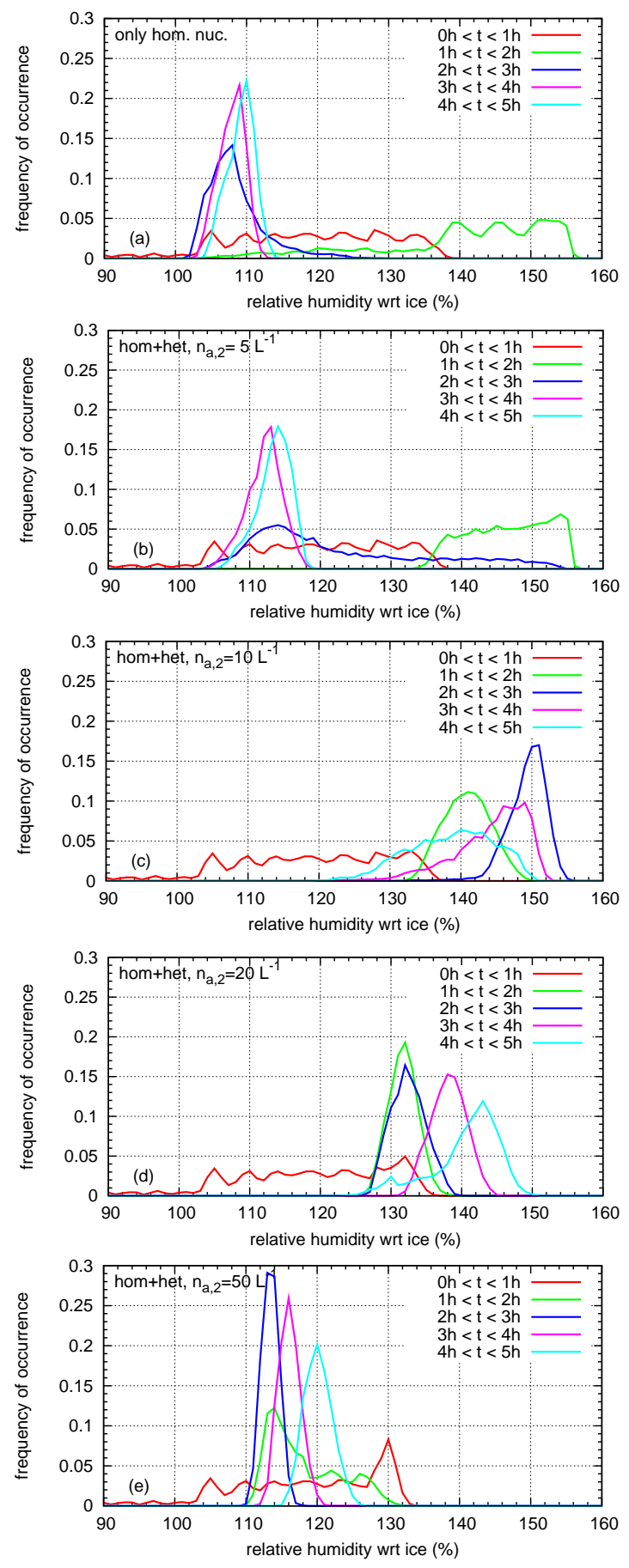

Fig. 12. Frequency distribution of the relative humidity in the altitude range $10400 \leq z \leq 10600 \mathrm{~m}$ collecting data from different time intervals ([0h:1 h], [1 h:2h], [2h:3h], [3h:4h], [4h:5h], colour code) for the different simulations $\left(n_{a, 2}=0 / 5 / 10 / 20 / 50 \mathrm{~L}^{-1}\right.$, panels (a) to (e), from top to bottom) during a synoptic updraught of $w=0.06 \mathrm{~m} \mathrm{~s}^{-1}$ including small scale temperature fluctuations.
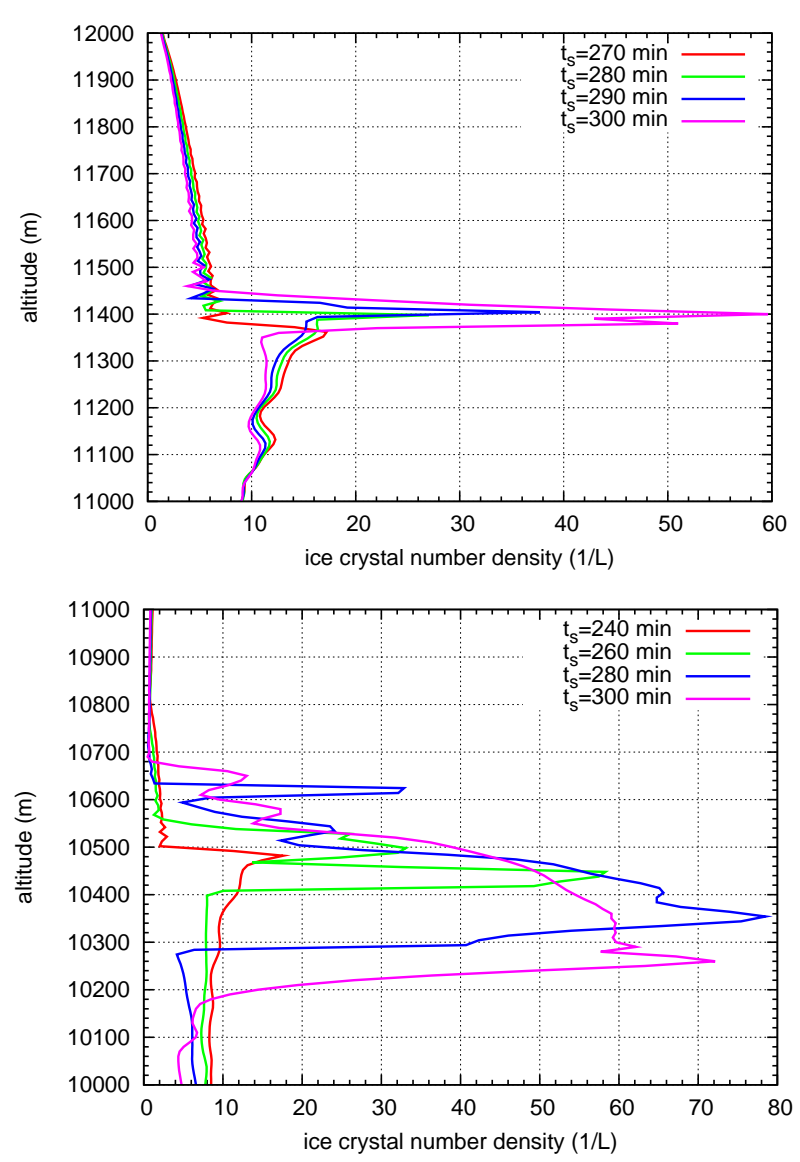

Fig. 13. Heterogeneous nucleation events below the cloud layer due to modification of the aerosol concentration by nucleation, sedimentation and evaporation of ice crystals are shown in representing heterogeneously formed ice crystals vs. height. Top panel: Simulation with constant updraught of $w=0.06$ for a initial ISSR in the range $10.5 \leq z \leq 11.5 \mathrm{~km}$. Bottom panel: Simulation with constant updraught of $w=0.08$ for a initial ISSR in the range $9.5 \leq z \leq 10.5 \mathrm{~km}$. In both cases, the initial IN concentration was $n_{a, 2}=20 \mathrm{~L}^{-1}$.

This shows how cirrus clouds can modify the background aerosol distribution by nucleation, sedimentation and evaporation (in this order) and create relatively large aerosol concentrations in sub-cloud layers. We see, large aerosol concentrations are not necessarily a product of correspondingly large source strengths, but may also be the result of cloud processes. In our simulations a layered structure of the background aerosol distribution resulted. Another effect of cloud processing is the alteration of microphysical and chemical IN properties; yet this has not been considered here.

\subsection{Size distributions}

Although we have to specify a certain a priori type of crystal size distribution, this does not mean that the cloud as a whole or certain layers in the cloud have this size distribution. 
While the size distribution is a monomodal log-normal in every grid box, the mean crystal sizes vary from grid box to grid box and are different in the two considered ice classes. Hence, over certain regions in a model cloud we can have biand even multimodal size distributions, which is in fact what we find.

Short (i.e. minutes) after a nucleation event mean crystal lengths are typically between 1 and $10 \mu \mathrm{m}$. One hour later we then find regions with mean crystal lenghts of $100 \mu \mathrm{m}$ and more. Maxima of (grid box mean) crystal lengths reach 200 to $300 \mu \mathrm{m}$.

Ice crystals formed heterogeneously are on average larger than ice crystals formed homogeneously because they form earlier and have less competition for excess vapour. Therefore, in a cloud that was predominantly formed by heterogeneous freezing we can expect to find larger ice crystals on average than in clouds formed predominantly by homogeneous nucleation. However, because in the latter cloud type there are much more ice crystals than in the former one, it might be that in total there are more large crystals in the latter than in the former cloud type.

\section{Conclusions}

We have used the recently developed ice microphysics scheme (Part 1a) for investigating the impact of heterogeneous nucleation on the life cycle of cirrus clouds driven by constant synoptic updraught $\left(w \leq 0.08 \mathrm{~m} \mathrm{~s}^{-1}\right)$ over at least $5 \mathrm{~h}$. Heterogeneous and homogeneous nucleation take place within the same environment and can influence each other. Related studies have been performed earlier with box models, but crystal sedimentation, temperature and wind fluctuations, usually not implemented in box models, introduce new effects. From our simulations we draw the following conclusions:

1. The rate $d R H i / d t$ (or $d S i / d t$ ) at the homogeneous nucleation threshold $\mathrm{RHi}_{\text {hom }}$ determines the number of ice crystals that are produced in the nucleation event. This conclusion is consistent with several published works (e.g. Kärcher and Lohmann, 2002; Ren and Mackenzie, 2005; Kärcher et al., 2006; Barahona and Nenes, 2008). In a situation without pre-existent ice crystals, it is the cooling rate $d T / d t$ or, indirectly, the uplift rate $w$ that determines (is proportional to) $d R H i / d t$.

2. Heterogeneous ice formation at relative humidities $\mathrm{RHi}_{\text {het }}<\mathrm{RHi}_{\text {hom leads to pre-existent ice that reduces }}$ $d R H i / d t$ due to its water uptake, hence reduces the number of ice crystals formed homogeneously later. This impeding effect of heterogeneous ice formation increases with increasing number of IN, and it is strong in particular when $\mathrm{RHi}_{\text {het }}$ is little below $\mathrm{RHi}_{\text {hom }}$. It is weak when $\mathrm{RHi}_{\text {het }}$ is low (i.e. when the background aerosol represents good ice nuclei), because this allows the heterogeneously formed ice to fall out from the ISSR before the homogeneous threshold is reached. The impeding effect is not simply linear in $\mathrm{RHi}_{\text {hom }}-\mathrm{RHi}_{\text {het }}$.

3. Sedimentation of the heterogeneously formed ice crystals leads to a downward ice concentration gradient in the cloud, which in turn causes an upward gradient of $d R H i / d t$. Hence the number of ice crystals forming homogeneously experiences an upward gradient as well. Homogeneous nucleation can be switched off in the lower cloud layers when a sufficiently large concentration of heterogeneously formed ice crystals is present. Fluctuations of temperature and random motions in the cloud weaken the latter effect.

4. There are generally three types of cloud structures, depending on the predominant ice formation process, i.e. homogeneous or heterogeneous freezing, and a mixed case. The latter is given when the IN concentration is roughly the critical number density from Eq. (21) in Gierens (2003) (typically $10 \mathrm{~L}^{-1}$ for the cases considered here). Mixed cases are prone to longlasting in-cloud supersaturation, while in either homogeneously and heterogeneously formed cirrus RHi relaxes to a quasi-stationary supersaturation of the order $10 \%$. The persistent supersaturation in each case is a consequence of the assumed constant uplift, resulting in constant cooling. We conjecture that mixed type clouds are characterised by similar timescales of cooling, crystal growth, and sedimentation.

5. The constant uplift together with crystal sedimentation leads to a thin zone of persistent ice supersaturation at the upper boundary of the ISSR and the cloud which periodically gives rise to a new homogeneous nucleation event.

6. Fluctuations of temperature and random motions in the cloud have the effect of leaving more water in the vapour phase, i.e. they enhance the in-cloud supersaturation phenomenon. The fluctuations have the biggest influence in the mixed cases where neither homogeneous nor heterogeneous ice formation dominates.

7. The cloud processes affect the background spatial distribution of the IN. In the cases studied here an initially uniform distribution is transformed into a layer nearly void of IN (most of the cloud layer) and a layer just beneath the cloud where IN are enriched. The ongoing cooling can eventually lead to new heterogeneous ice formation below the original cloud layer.

Cirrus clouds can form rather complex structures even in simple situations with constant cooling, quasi rectangular initial RHi profiles and a very simple heterogeneous nucleation parameterisation. To this complexity contribute (1) the 
highly nonlinear nucleation behaviour (on/off), (2) the supersaturation hysteresis involved in ice formation vs. evaporation (ice forms at substantial supersaturation but evaporates at subsaturation), and (3) the competition between various ice formation processes that act at different supersaturation thresholds. Whenever this game ends in a draw (i.e. neither nucleation process dominates) there appear zones of longlasting substantial supersaturation in a cirrus cloud.

Acknowledgements. We thank Piotr K. Smolarkiewicz for sharing his model and Andreas Dörnbrack for help in its application. We thank these two and Marcia Baker, Bernd Kärcher, Ulrike Lohmann, Thomas Peter, Olaf Stetzer and Marian de Reus for fruitful discussions. This study contributes to the DFG (German research foundation) project "Dünner Zirrus" (GI 333/1-1), to the DLR/HGF-project "Particles and Cirrus Clouds" (PAZI-2) and to Activity 5 of the European Integrated Project QUANTIFY. The numerical simulations were performed at the European Centre for Medium-Range Weather Forecasts (special project "Ice supersaturation and cirrus clouds").

Edited by: A. Nenes

\section{References}

Barahona, D. and Nenes, A.: Parameterization of cirrus formation in large scale models: Homogeneous nucleation, J. Geophys. Res., 113, doi:10.1029/2007JD009355, 2008.

Chen, T., Rossow, W. B., and Zhang, Y.: Radiative Effects of CloudType Variations, J. Climate, 13, 264-286, 2000.

Clark, T. and Farley, R.: Severe downslope windstorm calculations in two and three spatial dimensions using anelastic interactive grid nesting: A possible mechanism for gustiness, J. Atmos. Sci., 41, 329-350, 1984.

DeMott, P. J., Rogers, D. C., and Kreidenweis, S. M.: The susceptibility of ice formation in upper tropospheric clouds to insolu- ble aerosol components, J. Geophys. Res., 102, 19575-19584, 1997.

DeMott, P. D., Cziczo, A., Prenni, D., Murphy, S., Kreidenweis, D., Thomson, R., Borys, D., and Rogers, D. C.: Measurements of the concentration and composition of nuclei for cirrus formation, Proc. Nat. Acad. Sci., 100, 14655-14660, 2003.

Emanuel, K.: Atmospheric convection, Oxford University Press, 580 pp., 1994.

Fusina, F., Spichtinger, P., and Lohmann, U.: The impact of ice supersaturated regions and thin cirrus on radiation in the mid latitudes, J. Geophys. Res., D24S14, doi:10.1029/2007JD008449, 2007

Gierens, K., Schumann, U., Helten, M., Smit, H., and Marenco, A.: A distribution law for relative humidity in the upper troposphere and lower stratosphere derived from three years of MOZAIC measurements, Ann. Geophys., 17, 1218-1226, 1999, http://www.ann-geophys.net/17/1218/1999/.

Gierens, K.: On the transition between heterogeneous and homogeneous freezing, Atmos. Chem. Phys., 3, 437-446, 2003, http://www.atmos-chem-phys.net/3/437/2003/.

Grabowski, W. and Smolarkiewicz, P.: A multiscale anelastic model for meteorological research, Mon. Weather Rev., 130, 939-956, 2002.
Haag, W. and Kärcher, B.: The impact of aerosols and gravity waves on cirrus clouds at midlatitudes, J. Geophys. Res., 109, D12202, doi:10.1029/2004JD00457, 2004.

Heymsfield, A. and Iaquinta, J.: Cirrus crystal terminal velocities, J. Atmos. Sci., 57, 916-938, 2000.

Heymsfield, A. J. and Sabin, R. M.: Cirrus crystal nucleation by homogeneous freezing of solution droplets, J. Atmos. Sci., 46, 2252-2264, 1989.

Kajikawa, M. and Heymsfield, A.: Aggregation of ice crystals, J. Atmos. Sci., 46, 3108-3121, 1989.

Kärcher, B. and Lohmann, U.: A Parameterization of cirrus cloud formation: Homogeneous freezing of supercooled aerosols, J. Geophys. Res., 107(D2), 4010, doi:10.1029/2001JD000470, 2002.

Kärcher, B. and Ström, J.: The roles of dynamical variability and aerosols in cirrus cloud formation, Atmos. Chem. Phys., 3, 823838, 2003, http://www.atmos-chem-phys.net/3/823/2003/.

Kärcher, B. and Koop, T.: The role of organic aerosols in homogeneous ice formation, Atmos. Chem. Phys., 5, 703-714, 2005, http://www.atmos-chem-phys.net/5/703/2005/.

Kärcher, B., Hendricks, J., and Lohmann, U.: Physically based parameterization of cirrus cloud formation for use in global atmospheric models, J. Geophys. Res. 111, doi:10.1029/2005JD006219, 2006.

Koenig, L.: Numerical modeling of ice deposition, J. Atmos. Sci., 28, 226-237, 1971.

Korolev, A. and Mazin, I.: Supersaturation of Water Vapor in Clouds, J. Atmos. Sci., 60, 2957-2974, 2003.

Koop, T.: Homogeneous ice nucleation in water and aqueous solutions, Z. Phys. Chem. 218, 1231-1258, 2004.

Koop, T., Luo, B., Tsias, A., and Peter, T.: Water activity as the determinant for homogeneous ice nucleation in aqueous solutions, Nature 406, 611-614, 2000.

Khvorostyanov, V. and Curry, J.: The Theory of Ice Nucleation by Heterogeneous Freezing of Deliquescent Mixed CCN. Part II: Parcel Model Simulation, J. Atmos. Sci., 62, 261-285, 2005.

Khvorostyanov, V., Morrison, H., Curry, J. A., Baumgardner, D., and Lawson, P.: High supersaturation and modes of ice nucleation in thin tropopause cirrus: Simulation of the 13 July 2002 Cirrus Regional Study of Tropical Anvils and Cirrus Layers case, J. Geophys. Res., 111, D02201, doi:10.1029/2004JD005235, 2006.

Liu, X. and Penner, J. E.: Ice nucleation parameterization for global models, Meteor. Z., 14, 499-514, 2005.

Mace, G. G., Benson, S., and Vernon, E.: Cirrus Clouds and the Large-Scale Atmospheric State: Relationships Revealed by Six Years of Ground-Based Data, J. Climate, 19, 3257-3278, 2006.

Möhler, O., Field, P. R., Connolly, P., Benz, S., Saathoff, H., Schnaiter, M., Wagner, R., Cotton, R., Krämer, M., Mangold, A., and Heymsfield, A. J.: Efficiency of the deposition mode ice nucleation on mineral dust particles, Atmos. Chem. Phys., 6, 30073021, 2006, http://www.atmos-chem-phys.net/6/3007/2006/.

Murray, B. J., Knopf, D. A., Bertram, A. K.: The formation of cubic ice under conditions relevant to Earth's atmosphere, Nature, 434 202-205, 2005.

Murray, B. J.: Enhanced formation of cubic ice in aqueous organic acid droplets, Environ. Res. Lett., 3, 025008, doi:10.1088/17489326/3/2/025008, 2008a.

Murray B. J.: Inhibition of ice crystallisation in highly viscous 
aqueous organic droplets, Atmos. Chem. Phys., 8, 5423-5433, 2008b, http://www.atmos-chem-phys.net/8/5423/2008/.

Ovarlez, J., Gayet, J.-F., Gierens, K., Ström, J., Ovarlez, H., Auriol, F., Busen, R., and Schumann, U.: Water vapor measurements inside cirrus clouds in northern and southern hemispheres during INCA, Geophys. Res. Lett., 29(16), 1813, doi:10.1029/2001GL014440, 2002.

Peter T., Marcolli C., Spichtinger, P., Corti, T., Baker, M. B., and Koop, T.: When dry air is too humid, Science, 314(5804), 1399_ 1402, 2006.

Ren, C. and Mackenzie, A. R.: Cirrus parametrization and the role of ice nuclei, Q. J. Roy. Meteor. Soc., 131, 1585-1605, 2005.

Sassen, K. and Benson, S.: Ice nucleation in cirrus clouds: A model study of the homogeneous and heterogeneous modes, Geophys. Res. Lett., 27, 521-524, 2000.

Sassen K. and Dodd, G. C.: Haze aprticle nucleation simulations in cirrus clouds, and applications for numerical and lidar studies, J. Atmos. Sci., 46, 3005-3014, 1989.

Smolarkiewicz, P. and Margolin, L.: On forward-in-time differencing for fluids: an Eulerian/Semi-Lagrangian non-hydrostatic model for stratified flows, Atmos.-Oceans, 35, 127-152, 1997.

Smolarkiewicz, P., Margolin, L., and Wyszogrodzki, A.: A class of nonhydrostatic global models, J. Atmos. Sci., 58, 349-364, 2001.
Spichtinger, P., Gierens, K., Leiterer, U., and Dier, H.: Ice supersaturation in the tropopause region over Lindenberg, Germany, Meteorol. Z., 12, 143-156, 2003.

Spichtinger, P., Gierens, K., Smit, H. G. J., Ovarlez, J., and Gayet, J.-F.: On the distribution of relative humidity in cirrus clouds, Atmos. Chem. Phys., 4, 639-647, 2004, http://www.atmos-chem-phys.net/4/639/2004/.

Spichtinger, P., Gierens, K., and Wernli, H.: A case study on the formation and evolution of ice supersaturation in the vicinity of a warm conveyor belt's outflow region, Atmos. Chem. Phys., 5, 973-987, 2005, http://www.atmos-chem-phys.net/5/973/2005/.

Spichtinger, P. and Gierens, K. M.: Modelling of cirrus clouds Part 1a: Model description and validation, Atmos. Chem. Phys., 9, 685-706, 2009a, http://www.atmos-chem-phys.net/9/685/2009/.

Spichtinger, P. and Gierens, K. M.: Modelling of cirrus clouds Part 1b: Structuring cirrus clouds by dynamics, Atmos. Chem. Phys., 9, 707-719, 2009b, http://www.atmos-chem-phys.net/9/707/2009/.

Vali, G.: Nucleation terminology, B. Am. Meterol. Soc., 66, 14261427, 1985.

Zobrist, B., Marcolli, C., Pedernera, D. A., and Koop, T.: Do atmospheric aerosols form glasses?, Atmos. Chem. Phys., 8, 52215244, 2008, http://www.atmos-chem-phys.net/8/5221/2008/. 